Supplement of

\title{
Technical note: A new approach to discriminate different black carbon sources by utilising fullerene and metals in positive matrix factorisation analysis of high-resolution soot particle aerosol mass spectrometer data
}

Zainab Bibi et al.

Correspondence to: Zainab Bibi (zainab.bibi@manchester.ac.uk) and James D. Allan (james.allan@manchester.ac.uk)

The copyright of individual parts of the supplement might differ from the article licence. 
Table S1: Pearson correlation coefficients between different BC measurements, specifically rBC (HR-SPAMS) with eBC and BrC (AE31) and eBC (MAAP)

\begin{tabular}{|lc|}
\multicolumn{2}{|c|}{ rBC (HR-SP-AMS) } \\
\hline & Pearson Coefficient \\
\hline eBC (AE31) & 0.98 \\
\hline BrC (AE31) & 0.96 \\
\hline eBC (MAAP) & 0.95 \\
\hline
\end{tabular}

Table S2: Correlation between BC (HR-SP-AMS) and CIMS measurements

\begin{tabular}{|cccc|}
\hline HR-SP-AMS & \multicolumn{2}{c|}{ CIMS DATA } \\
\hline & HCN & HCNO & HONO \\
\hline & $\begin{array}{c}\text { Pearson } \\
\text { Coefficient }\end{array}$ & $\begin{array}{c}\text { Pearson } \\
\text { Coefficient }\end{array}$ & Pearson Coefficient \\
\hline rBC (HR-SP-AMS) & 0.88 & 0.77 & 0.89 \\
\hline
\end{tabular}

Table S3: Correlation between HR-Aerosols species Vs Aerosol and Gases (AMS)

\begin{tabular}{|ccc|}
\hline HR Aerosol Species & Aerosol and Gases & Pearson Coefficient \\
\hline rBC & BC_(ugm $\left.{ }^{-3}\right)$ & 0.95 \\
\hline HROrg & Org_(ugm $\left.^{-3}\right)$ & 0.92 \\
\hline HRNH4 & $\mathrm{NH}_{4}\left(\mathrm{ugm}^{-3}\right)$ & 0.92 \\
\hline HRNO3 & $\mathrm{NO}_{3}\left(\mathrm{ugm}^{-3}\right)$ & 0.86 \\
\hline HRSO4 & $\mathrm{SO}_{4}\left(\mathrm{ugm}^{-3}\right)$ & 0.91 \\
\hline HRChl & $\mathrm{Chl}_{-}\left(\mathrm{ugm}^{-3}\right)$ & 0.99 \\
\hline
\end{tabular}


PMF Factorisation factors solution without inclusion of Fullerenes signals:

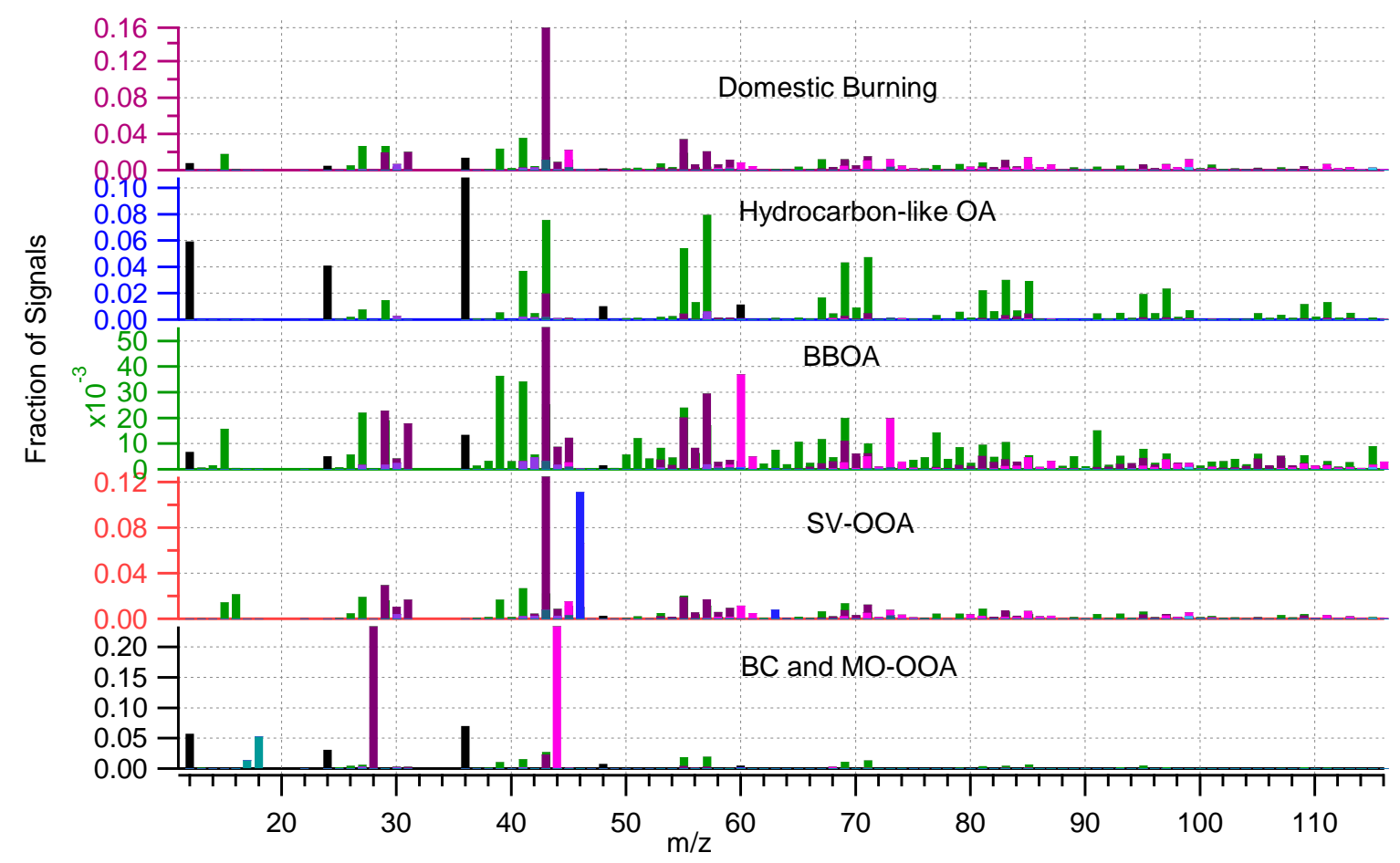

Cx

$\mathrm{CH}$

$\mathrm{CHO1}$

CHOgt1

CHN

CHO1N

CHOgt1N

CS

$\mathrm{HO}$

Figure S1a Mass Spectra of five factors solution (without inclusion of fullerene signals).

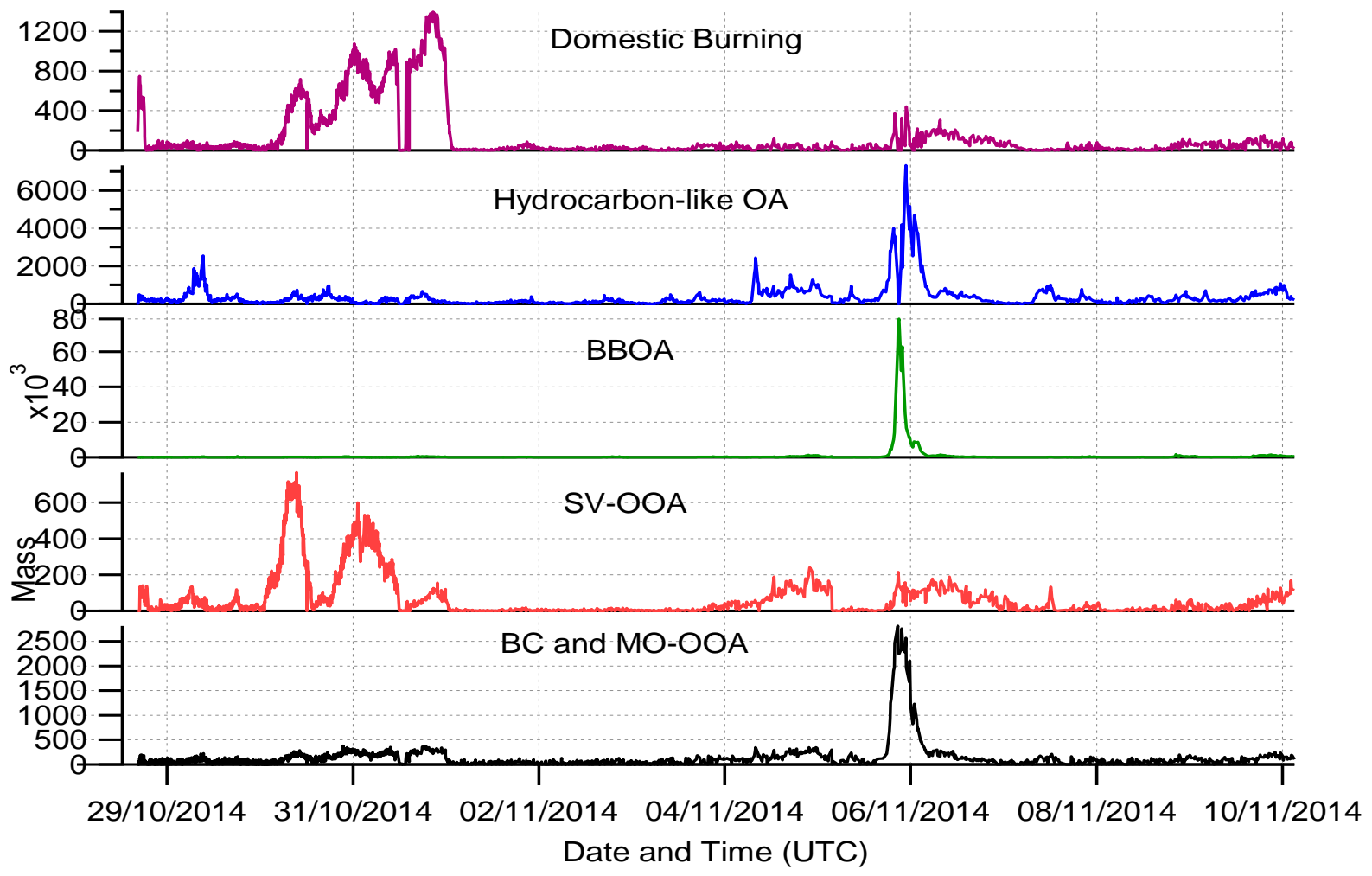

Figure S1b time series of five factors (without the inclusion of fullerene data). 
PMF Factorisation factors solution with inclusion of Fullerenes signal

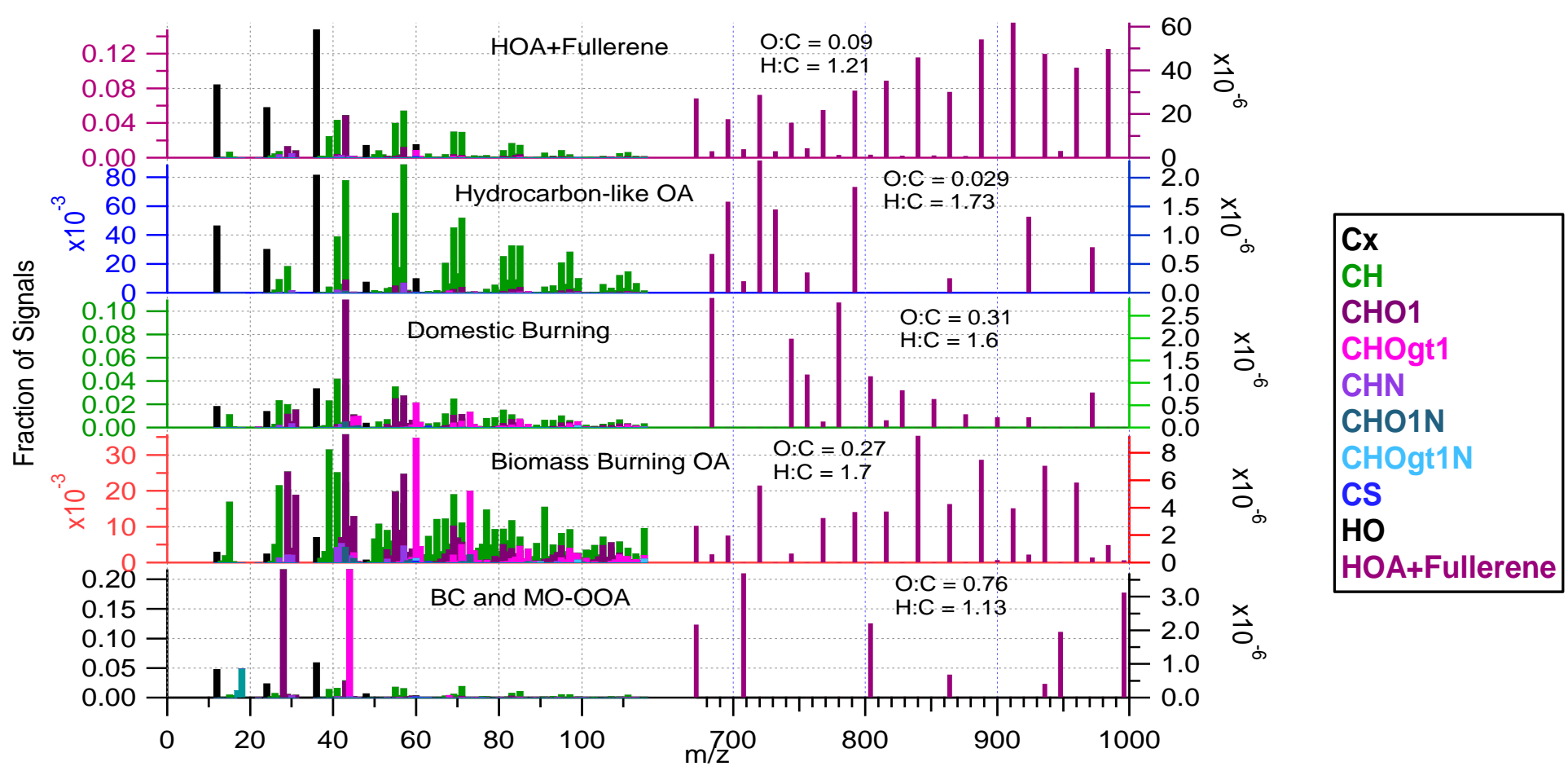

Figure S2a: PMF five factors source profile (factor $1=\mathrm{BC}$ and MO-OOA, factor $2=\mathrm{BBOA}$, factor $3=$ Domestic burning OA, factor 4 = Hydrocarbon-Like OA, factor 5 = Fullerene). (with the inclusion of Fullerene data)

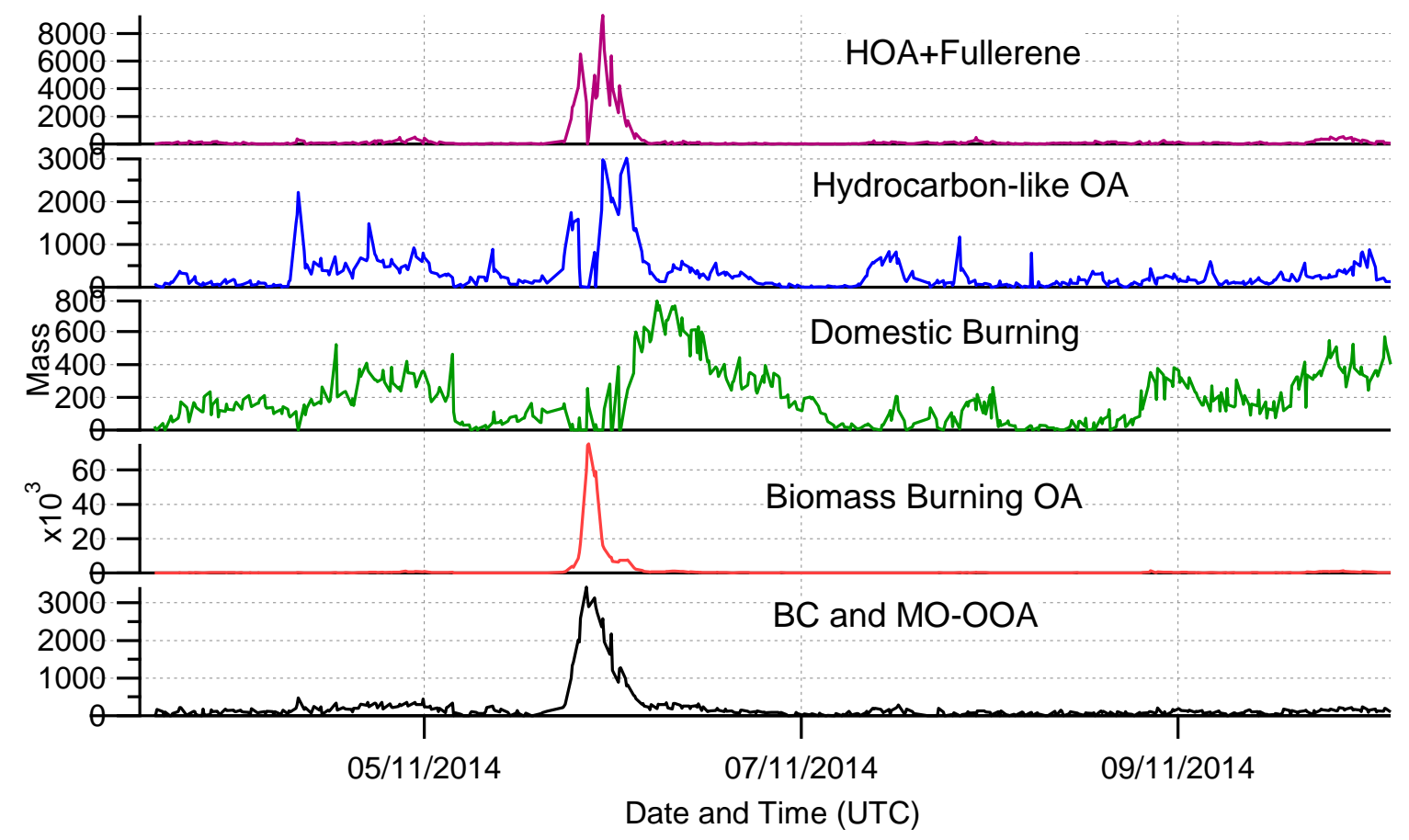

Figure S2b: The time series of five factor solution (with the inclusion of Fullerene data). 


\section{Model Error modification:}

Here we use the term 'model' error to refer to the additional error term that can be added as part of the PET toolkit, whereby additional error is added proportional to the signal, as opposed to the square root of the signal as is done in the standard AMS error model. In this study, the model error parameter was modified from 0.00, 0.05 and 0.10 by following the recommendations made by Paatero and Hopke (2003). While this is not always done in AMS PMF analysis, this is done here to decrease the signal-to-Noise Ratio (SNR) of the high signals that would otherwise dominate the factorisation. Firstly, the PMF was run with 0.0 model error and Fig. S3a, b depicts that SNR was very high i.e. 1200 SNR for some peaks. For a model error parameter of 0.05, fig. S4a, b shows that SNR was decreased i.e. 18 SNR and improved overall signals of sources, particularly for the fullerenes. For a value of 0.10 , the maximum SNR is further reduced to 10 (fig. S5a, b), meaning the error was now dominated by the 'model error' term, and this delivered the most satisfactory solution in terms of distinctive mass spectra, particularly for the fullerenes.

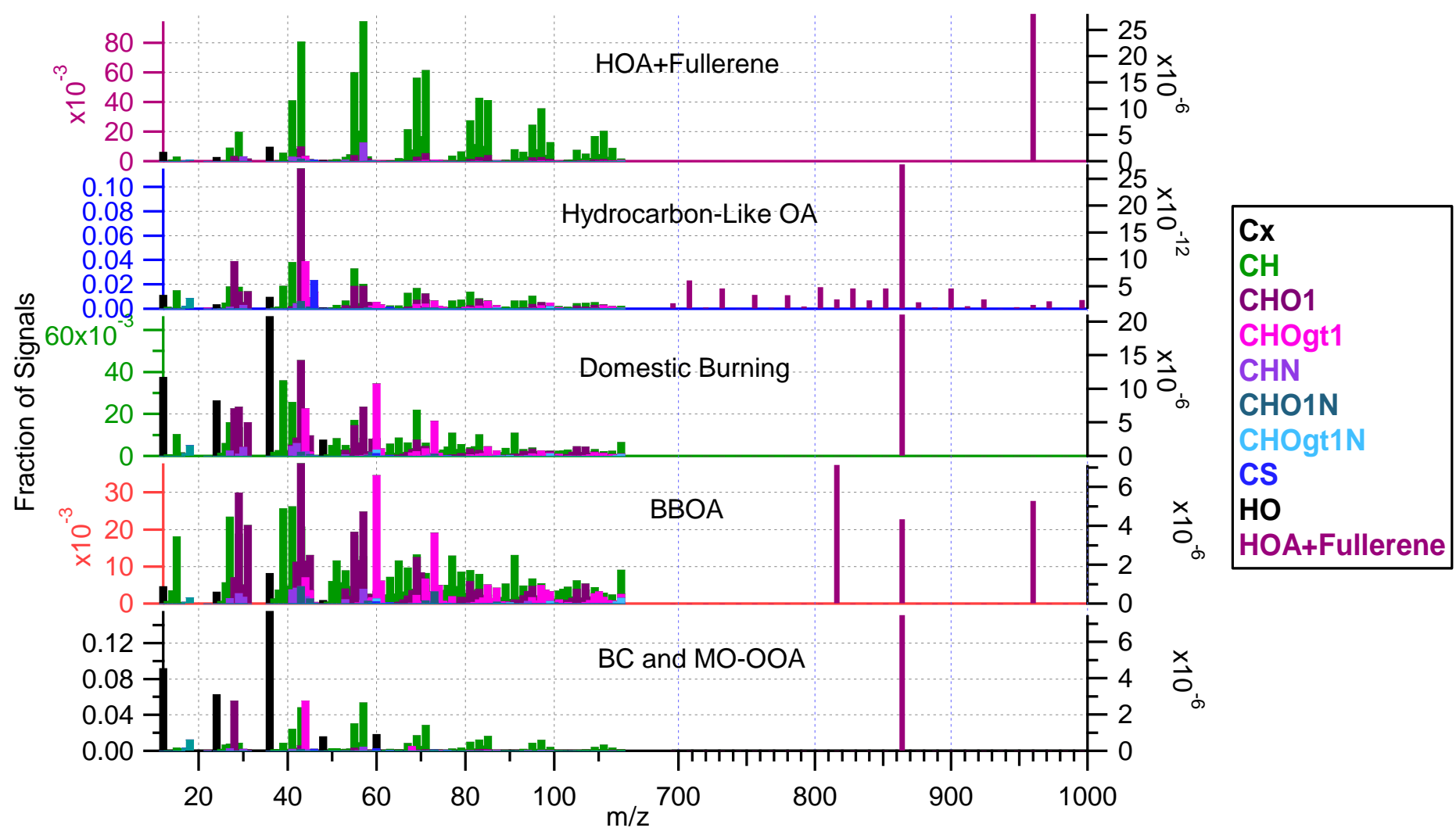

Fig S3a PMF five factors profile detected by the model error of 0.00 


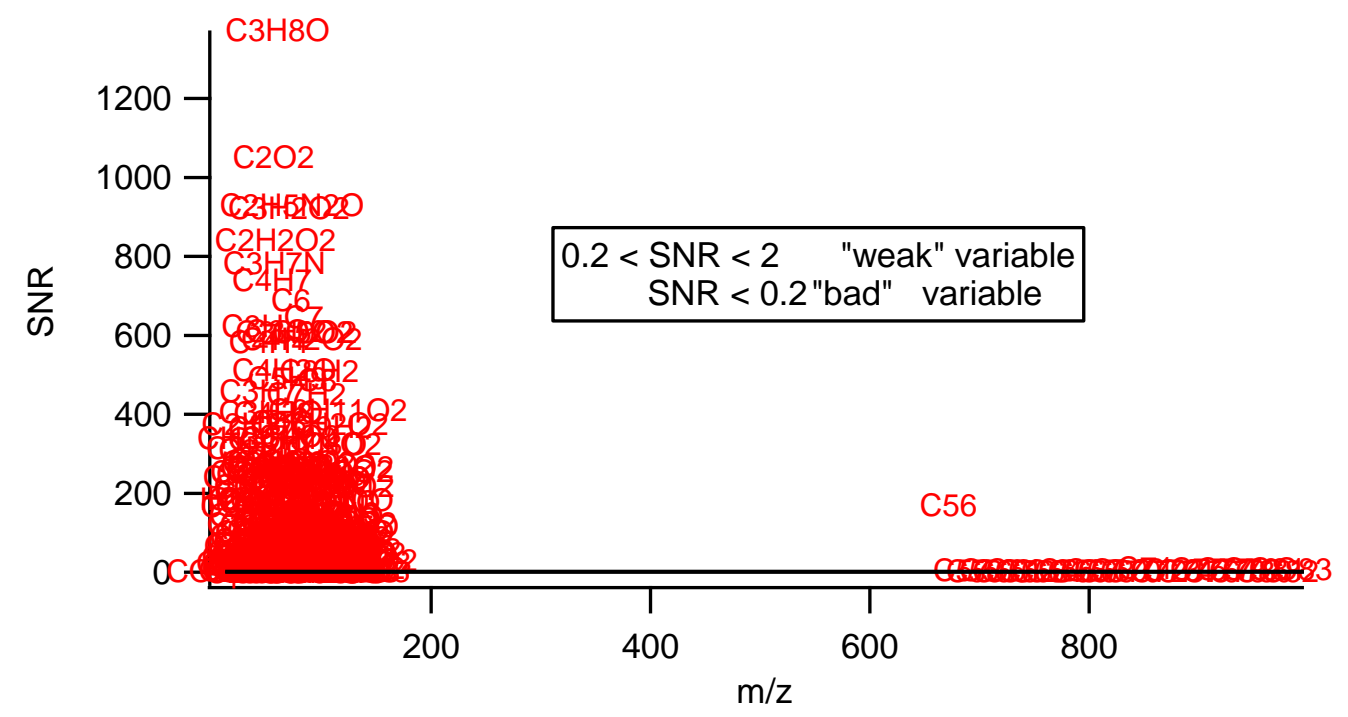

Figure S3b shows the SNR of organics and fullerenes with no modification in the model error value i.e. 0.00.

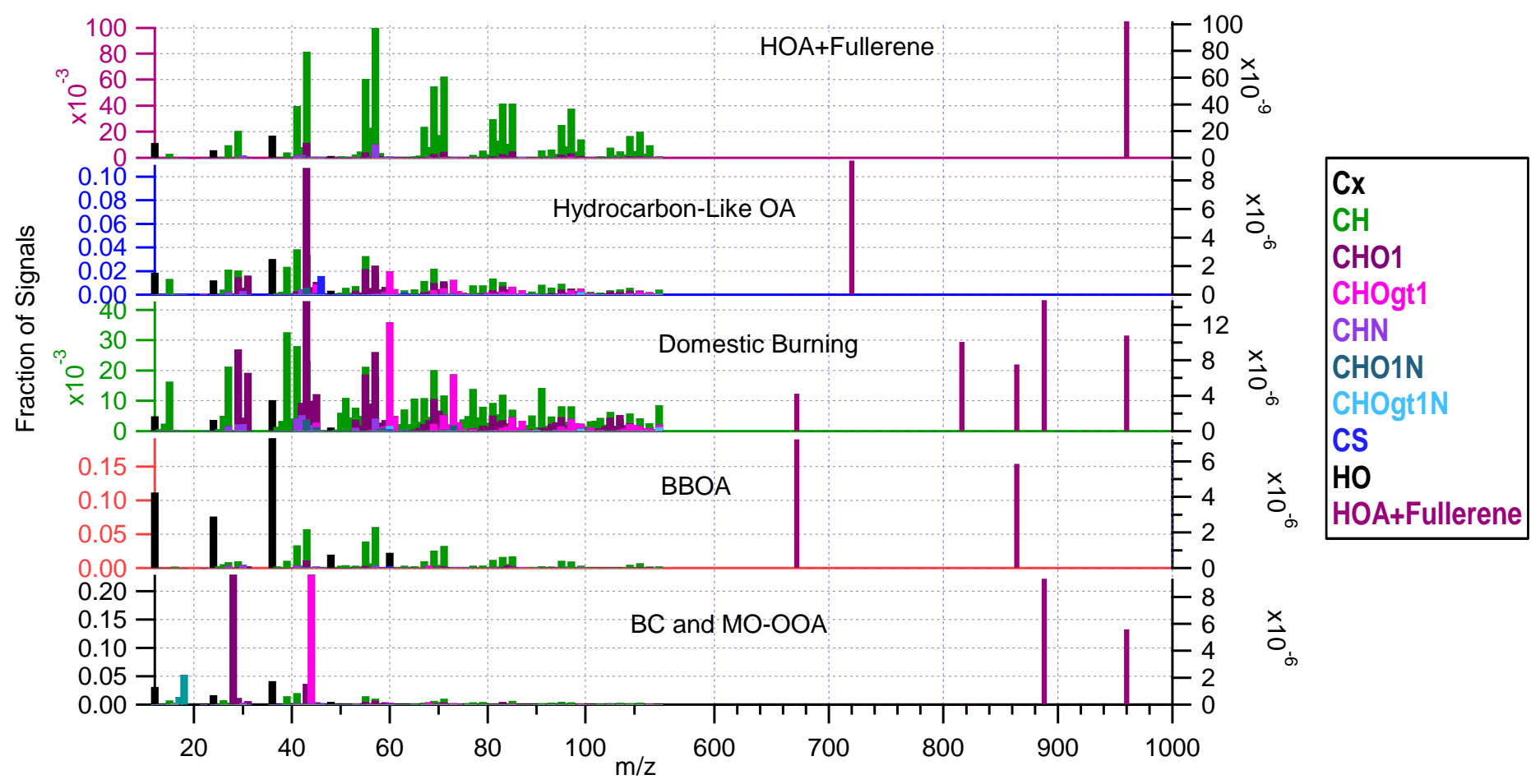

Fig S4a PMF five factors profile detected by the model error 0.05 


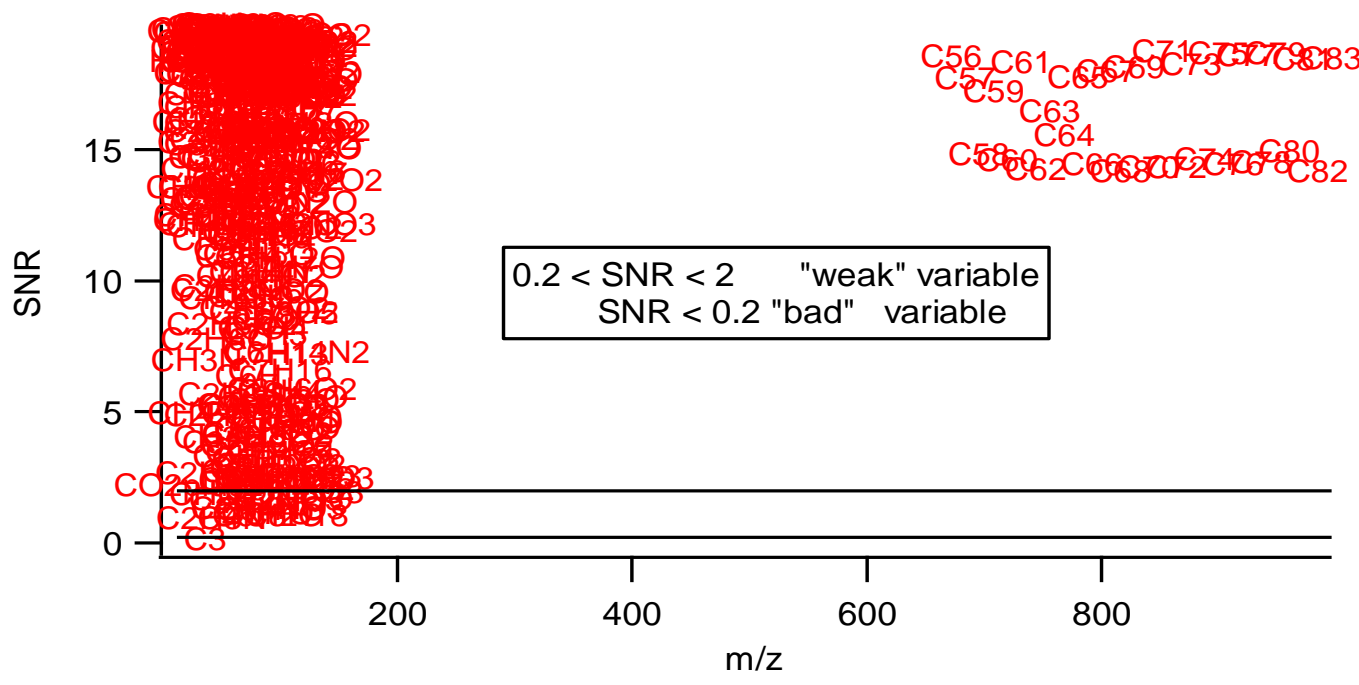

Figure S4b shows the SNR of organics and fullerenes with little modification in the model error value i.e. 0.05

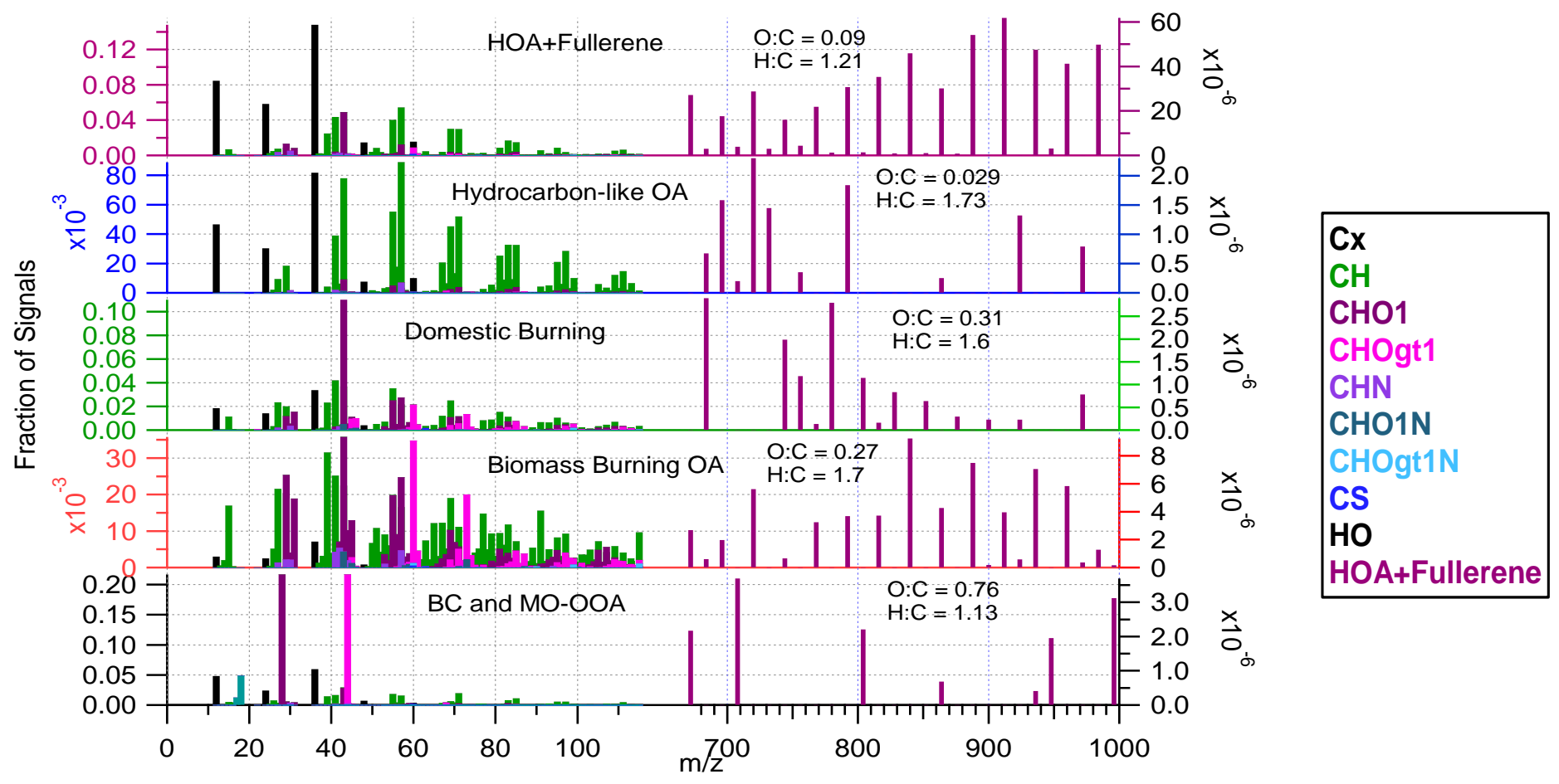

Fig S5a PMF five factors profile detected by the model error 0.10 


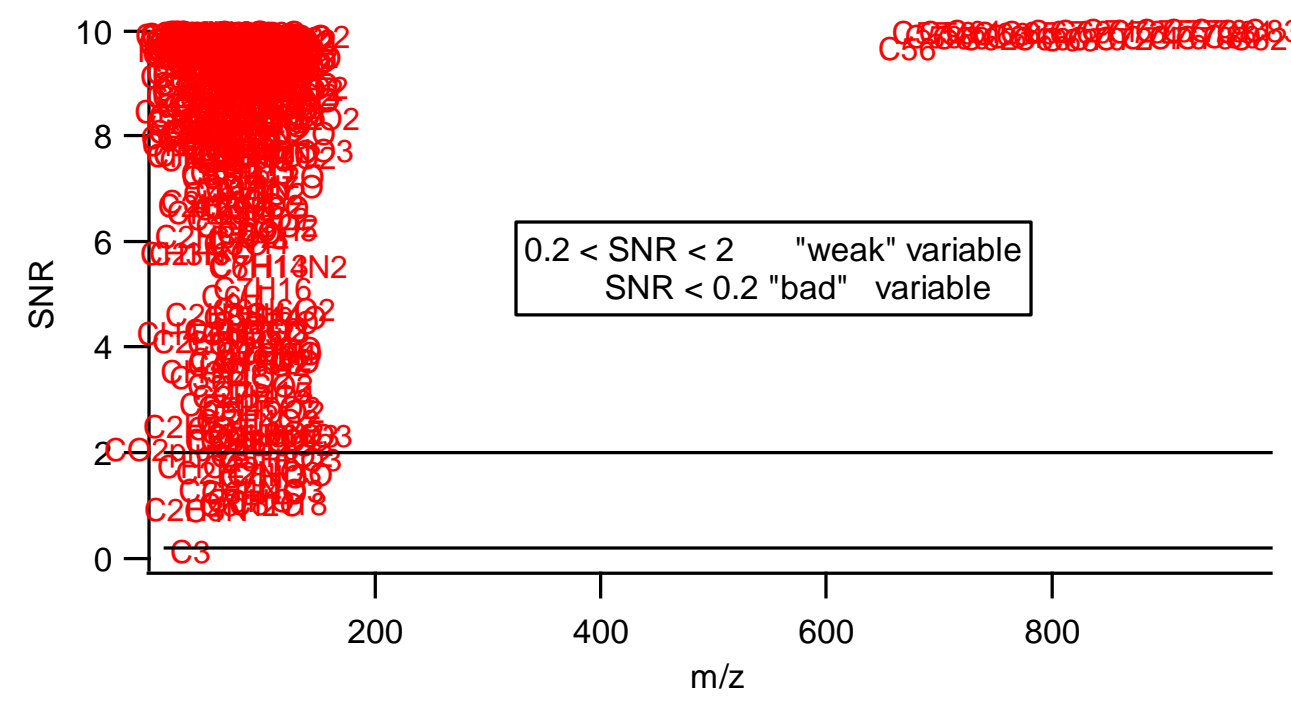

Figure S5b shows the SNR of organics and fullerenes with more modification in the model error value i.e. 0.10.

\section{PMF factors solution selection:}

A range of solutions were obtained using different parameters as part of the PMF analysis and here we present the reasons behind the choice of solution used in the paper. Regarding the number of factors, a 5-factor solution was chosen instead of 6-factor solution because all the five factors are separated from one another and represent a specific soot source (fig S6a, b). In comparison, the 6-factor solution has two 'split' factors representing the same emissions. These are factor 2 and factor 4 in figure S7b and represent domestic wood burning sources because their peaks were evident before and after the bonfire night event (fig. S7a, S7b).

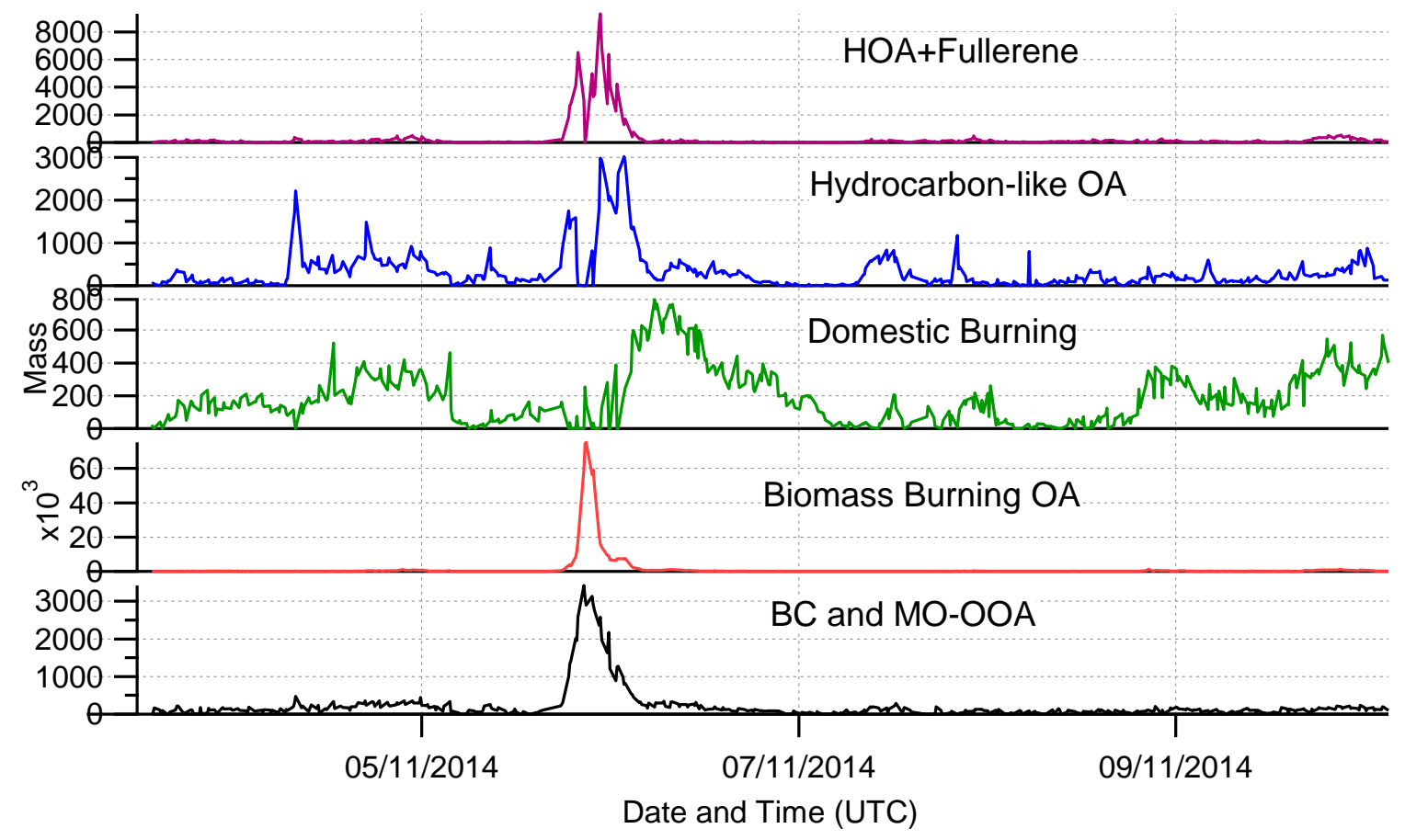

Figure S6a: Time series of five factors solution detected separately under the condition of 0.10 model error. 


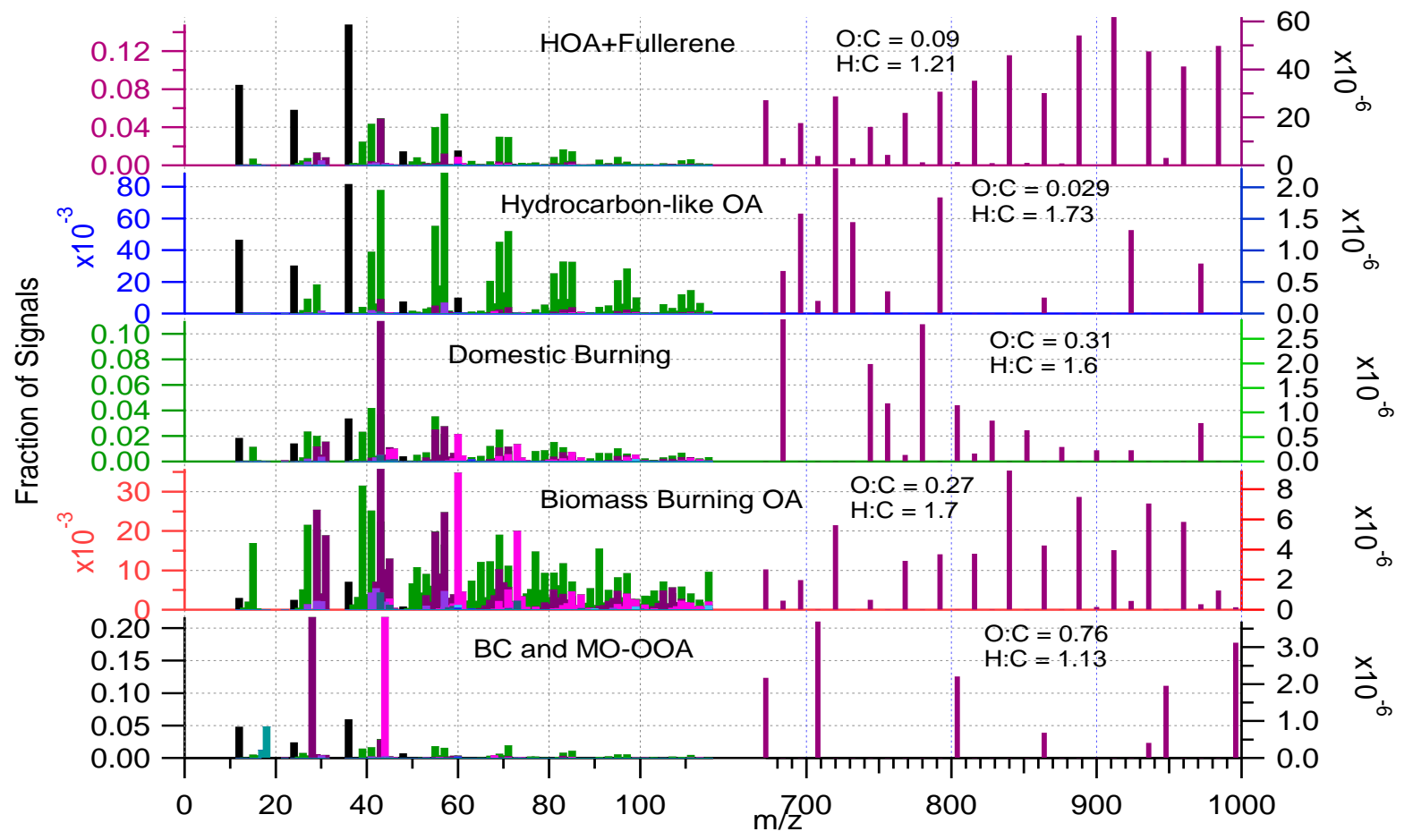

Cx $\mathrm{CH}$ CHO1 CHOgt1 CHN CHO1N CHOgt1 CS HO HOA+Fullerene

Figure S6b: The factor profile of five factors solution detected separately under the condition of 0.10 model error.

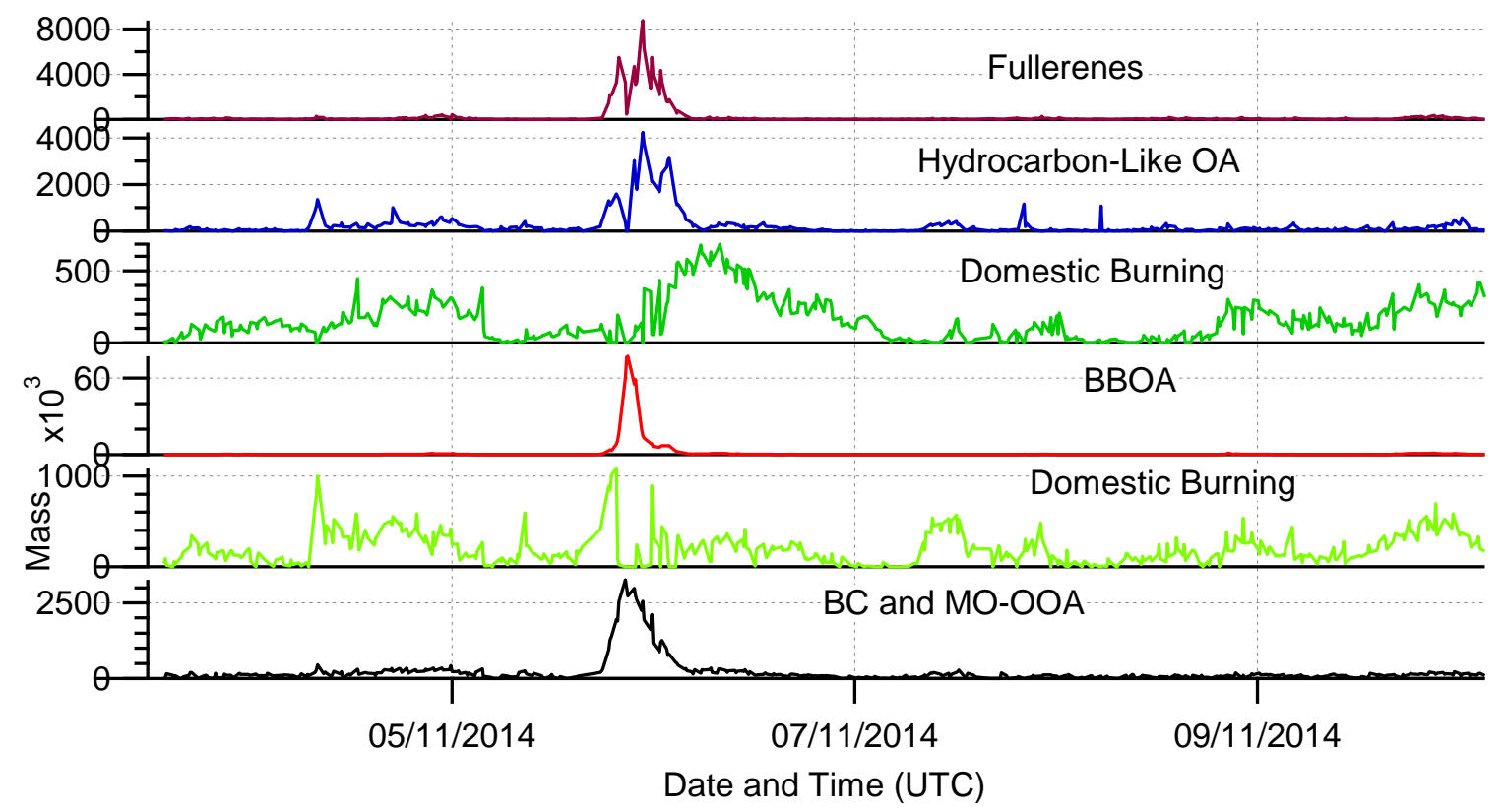

Figure S7a: Time series of six factors solution in which two same factors are split in to two different factors i.e. 2 and 4 under the condition of 0.10 model error. 


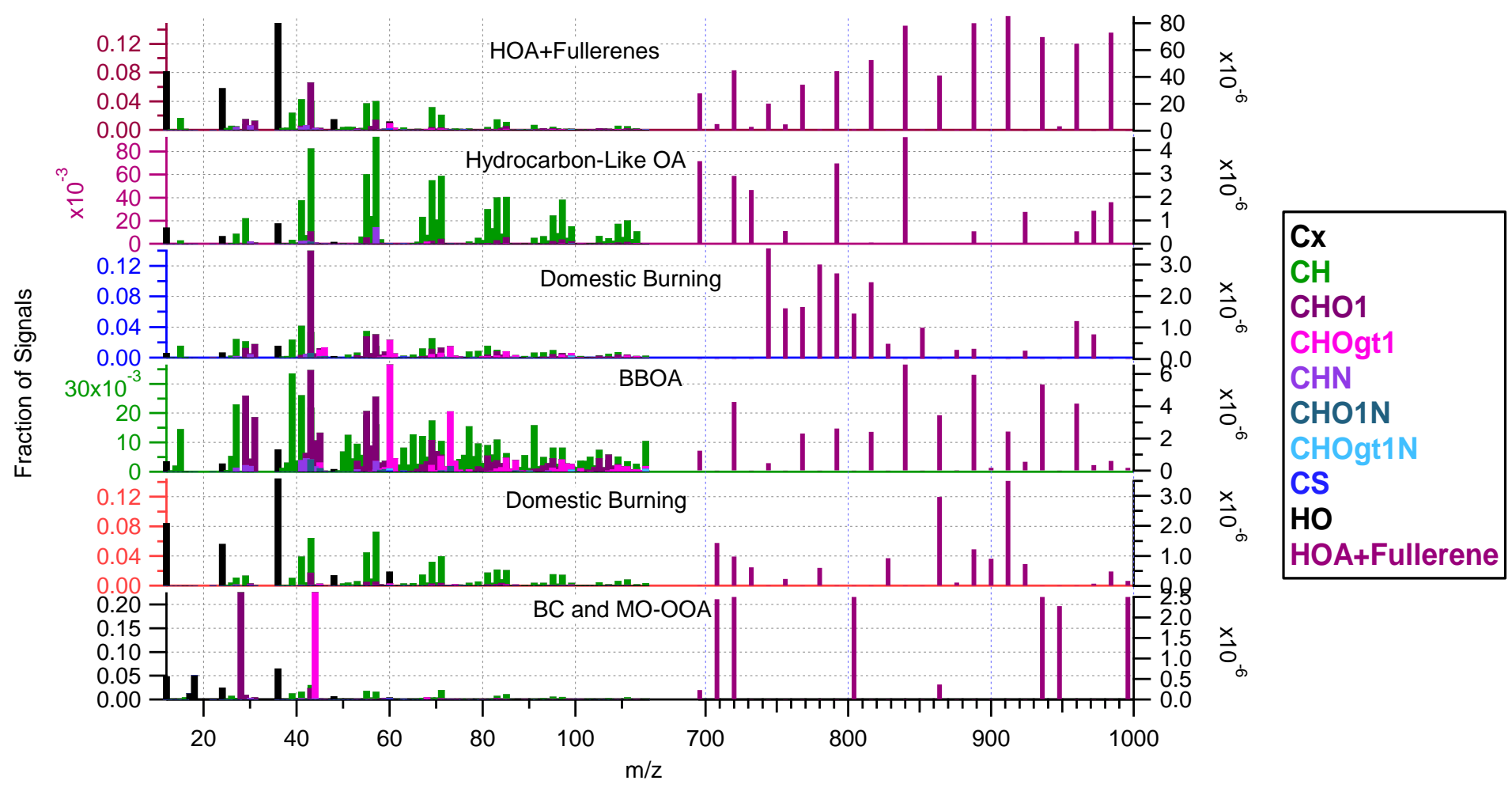

Figure S7b: Factor profiles of the 6-factor solution in which factor 2 and 4 have the same $\mathrm{m} / \mathrm{z}$ spectrum, under the condition of 0.10 model error. 